\title{
The Challenge of Detect and Characterize the Early Risk in Living Kidney Donor Transplant Col4a Nephropathy
}

\author{
Fidalgo Diaz $\mathbf{M}^{1}$, Abuward Abu sharkh $\mathrm{I}^{4 *}$, Garcia Murias $\mathbf{M}^{2}$, Garcia Gonzalez $\mathbf{M A}^{2}$, Alonso Valente $\mathrm{IR}^{1}$, \\ Pintos Martinez $\mathrm{E}^{3}$ and Diaz Rodriguez $\mathrm{C}^{1}$ \\ ${ }^{1}$ Department of Nephrology, University Hospital Complex of Santiago de Compostela, Spain
}

${ }^{2}$ Department of Genetics and Biology, University Hospital Complex of Santiago de Compostela, Spain

${ }^{3}$ Department of Pathological Anatomy Service, University Hospital Complex of Santiago de Compostela, Spain

${ }^{4}$ Department Nephrology, Emirates European Hospital, United Arab Emirates

*Corresponding author: Abuward Abu sharkh I, Nephrology department, Emirates European Hospital, Sharjah, United Arab Emirates.

Received Date: October 14, 2019

Published Date: November 15, 2019

\section{Abstract}

Summary: Kidney transplantation confers the best prognosis for patients with end-stage renal disease (ESRD) and living kidney donation confers superior outcomes to the deceased kidney donation. Safety in living kidney donation has been widely accepted, but new recent evidence has revealed a relative ESRD risk for donors. Why this ESRD occurs in living kidney donors (LKD) is unclear. All studies to date have not shown any evidence about a grow incidence of any classic risk factor (hypertension, diabetes, albuminuria...) for ESRD in the well selected donors, however, we could say that some donors groups present with higher risk, specially related donors.

Methods: Two families of our cohort, two of them with a not expected and dramatically early LKD kidney damage after renal transplantation DNA sequencing studies have been performed.

Results: A variant of COL4 to date not pathological considered, was detected, but any mutation , is clearly identified; this COL4 nephropathy would have an important pathogenicity burden, in terms of refractory nephrotic syndrome (NS), ESRD or proteinuria.

Conclusion: Clinical phenotype in COL4AN can be diverse and confused and are a challenge for the clinicians as occurs in the LKD candidate study. The determinants of phenotype expression remains unknown. COL4N is a relative common disorder and will remain to clarify if it has a role in the LKD glomerulonephritis related ESRD. More data are needed.

Abbreviations: AS: Alport Syndrome; CKD: Chronic Kidney Disease; COL4A: Collagen 4A; ESRD: End Stage Renal Disease; FSGS: Focal and Segmental Glomerulosclerosis; LKD: Living Kidney Donor; NS: Nephrotic Syndrome; NGS: Next Generation Sequence; SNP: Single Nucleotide Polymorphism; TBMN: Thin Basement Membrane Nephropathy; GWAS: Genome Wide Association Study

\section{Living Kidney Donor Safety}

Kidney transplantation confers the best prognosis for patients with end stage renal disease and living kidney donation confers superior outcomes to deceased kidney donation, these evidences were show in all major series comparing both groups, living donor and deceased donor [1-4]. Determining risk is critical for informing future donor candidates [5], donors will always be at risk for surgical complications or developing diseases later in life. For this purpose, many studies have been reported in recent years. Perioperative death is extremely rare and subsequent survival rates are comparable with healthy non-donors [6-8]. From the beginning, the scientific community has believed in a possible long-term risk related to living with a single kidney which could suffering for trauma or tumors but not definitely studies were done about it. Several studies have analyze a possible end-stage renal disease (ESRD) increased risk, comparing with general population but no differences between groups were found [9-11].

Another classical concern to consider in the long-term safety of living kidney donations were if mild proteinuria and hypertension 
occurs following kidney donation. An important and recent study about long-term changes in blood pressure in LKD did not show an increased risk of hypertension in the well selected donors, in addition, no presence of higher albuminuria has been detected [12]. The small size and averaging $<10$ years may limit these results. Regardless a controversy persists.

A recent meta-analysis did not find a higher risk for all- cause mortality, cardiovascular disease, hypertension, type 2 diabetes, and adverse psychosocial health outcomes on donors, but describes a higher relative risk (RR) for end-stage renal disease (ESRD). Despite the increased RR, the absolute risk for these outcomes remains low [13]. This absolute risk of CKD in living donors was also described by Muzaale, et al. specifically, an exponentially over time risk. Kidney donors had an increased risk of ESRD during a median of 7.6 years [14] . Also, several studies have found a relationship between race, time and risk of ESRD among LKD [15-21].

Obesity is another risk factor for donors ESRD development. Among healthy non-donors, body mass index above 30 is associated with a $16 \%$ increase in risk of end-stage renal disease. Locke et al. revealed that a greater body mass index was associated with higher risk [22,23]. Also, visceral obesity may affect the renal function after donor nephrectomy [24]. Massie, et al. [23] show how estimated risk varied widely according to donor characteristics, in general donors who had a first-degree biological relationship to the recipient, male, older age and black donors had increased risk of ESRD. Also, Matas, et al. [25] recently shows a first-degree relative association.

Except, maybe for obesity or IMC above $27 \mathrm{~kg} / \mathrm{m}^{2}$, not clear early incident classical risk factor (hypertension, diabetes, albuminuria) has been highlighted as the cause of ESRD in a well selected living donor. ESRD in live kidney donors has traditionally been reported in studies averaging $<10$ years but the risk of a possible diabetic and hypertensive ESRD increases exponentially overtime, so everything described above should always be interpreted with caution. On the other hand, glomerulonephritis may cause early ESRD in LKDs $[20,26]$. In a database analysis with 126 LKD with ESRD, the most frequent diagnosis was glomerulonephritis [20].

\section{Glomerulonephritis, Collagen 4a Nephropathy and Living Kidney Donor Risk}

Recently we are knowing more about the genetic factors behind glomerulonephritis; many glomerulonephritis has significant genetic risk which may manifest through kidney intrinsic or systemic mechanisms. Heritable kidney intrinsic predisposition to glomerulonephritis will result in increased risk of glomerulonephritis recurrence in kidneys transplanted from genetically related donors [27] but also is high probably can result on donor kidney damage. ESRD in the early post donation period is unlikely to result from a classical risk factor of CKD because these conditions are relative contraindications to live kidney donation, however, it has been reported that glomerulonephritis can cause ESRD [11,20,26]. Glomerulonephritis may be associated with CKD risk in those with normal renal function $[28,29]$ and may also be associated with a genetic heredity risks in donors who are biologically related to recipients with glomerulonephritis-ESRD $[30,31]$.

The susceptibility factors, genetic risk and molecular mechanisms that can develop glomerulonephritis in DV are not well understood and are poorly characterized. Unfortunately, there is an insufficient data reported of these entities, characteristics and his repercussion on LKD transplant results. As the literature has been recently described, there is a high presence of mutations in collagen 4A (COL4A) in glomerular disorders, including Focal and Segmental Glomerulosclerosis (FSGS) and others not well characterized [32]. COL4 nephropathy comprises benign familial microscopic hematuria- thin basement membrane nephropathy (TBMN), X-linked Alport syndrome (AS) and also autosomal recessive and dominant AS. X-linked form of AS is caused by hemizygous mutations in COL4A5 gene, the other forms are caused by mutations in the COL4A3 or COL4A4 genes. More recently, the spectrum of COL4A nephropathy has expanded to include late onset FSGS that develops on top of TBMN in later life [32,33] Also, other reports showed that some patients with a primary diagnosis of familial FSGS proved to have variants in COL4A genes [34].

TBMN is a not infrequent finding in the general population, it may be the underlying cause and the explanation for many familial and sporadic cases of late-onset FSGS

As a clinical example about what remains to be solved in living transplantation and how this expanding spectrum of COL4A nephropathy can play and important role, we propose a discussion about two dramatic cases from our cohort with unexpected outcome.

\section{Familiar COL4A Hidden Risk}

We analyzed two families with post-donation donor kidney damage, starting from an initial successfully donor selection. Not hereditary or familial nephropathy were described or initially suggested.

\section{Family 1}

The main case of the family is a woman of 61 years old, who donates a kidney to her son in 2008, fulfilling the criteria for selection donor with normal urinary sediment and normal renal function and no comorbidities. The son was already a second transplant, after a primary renal failure in childhood of unidentified cause. No deafness or eye abnormalities were present, father was already dead and no suspicious of hereditary familial nephropathy were present. The first (from deceased donor) renal transplant was done on 1998. In 2008 the son received a second renal transplant from his mother after chronic renal allograft nephropathy, one year later the mother develops a steroid resistant NS with a biopsy showing a FSGS, refractory and resistant also to therapy with tacrolimus and rituximab. Finally, in 2017 she develops ERSD that requires hemodialysis. The son maintains normal renal function. A suspicion of a renal family entity and a next-generation DNA sequencing (NGS) analysis was made. 


\section{Family 2}

The main case was a 24 years old girl with ESRD secondary to a GFS and resistant NS. Diagnosis was made in childhood and she receives a deceased kidney in 2010 after developing ESRD in 2006 at the age of 12 . She received a second renal transplant from her father in 2017 after chronic allograft nephropathy. The father correctly passing the screening for donor, and also no suspicious of hereditary familial nephropathy were present at this moment. Actually 4 months after the transplant mild proteinuria of $300-500 \mathrm{mg}$ is observed on the donor (and also on recipient) a find that previously were persistently negative and would have contraindicated the donation. Another NGS analysis was made.

\section{Results}

The gene variant identified in exon 42 of the COL4A4 gene (chr2: NM_000092: exon42: c.3979G>A: p. V1327M), This missense variant involves a change of an amino acid Valine (Val, V, non-polar amino acid) by a Methionine (Met, M, non-polar amino acid). This change has been previously found in normal chromosomes and some authors described this variant like a polymorphism. We studied the functional impact of this changed with programs predictors and, in most cases, they give nonpathogenic scores to this variant (SIFT: Tolerant -T-, Polyphen: Benign -B-, Mutation Taster: Polymorphism automatic -P-; Mutation Assessor: Low -L-; FATHMM: Deleterious -D-; PROVEAN: Neutral -N-, MetalLR: Tolerated -T-, MetalSVM: Tolerant -T-, CADD_Score: 14.35). These parameters would not classify the variant as pathogenic. $[35,36]$. Some evidence suggests that genetic factors other than mutations in these collagen $4 \mathrm{~A}$ genes may affect underlying clinical features.

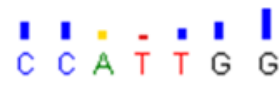

220

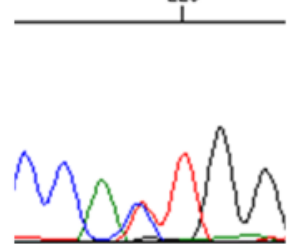

(A)

Figure 1: Electropherograms showing $\mathrm{V} 1327 \mathrm{M}$ variation found in COL4A4 gene in family 1 and 2. (A) Sequence of DNA from mother, who was heterozygous for the $C$ to $T$ variation. $(B)$ Sequence of DNA from child, who was homozygous for the $C$ to $\mathrm{T}$ variation.

Family 1 represents a dramatic case of ESRD in a previously clinically normal donor without urine abnormalities or CKD where a genetic family factor masked or not well determined at time can lead the donor to a severe and resistant NS and early ESRD. The complexity of this case is observed in how hyperfiltration has a dramatic effect on the mother This Col4A4 variant in heterozygosis, as present in other families of our cohort seems to be associated with a significant pathogenicity burden, contrary to believe at time so It is highly probable that another not identified genetic factor (in addition to hyperfiltration) results in a severe clinical phenotype related to a GBM disorder (FSGS). The son has the same mother's variant but in homozygosis and debuted with ESRD of not identified cause in the pediatric age and the transplant from his mother was done also ten years ago, the important similarity that exists in both family's 1 and 2 is striking. In family 2 a few months after the daughter's transplant (motivated by a resistant NS) a presence of proteinuria previously and clearly absent on the father. We will continue to closely monitor this finding.

On the other hand, and contrary to the expected, the son of family 1 has not developed any renal pathological event at time suggesting that another factor has to play also an important role here and could be related to the age. This reflects the biological characteristic of glomerulonephritis, in some instances, they may evolve relatively rapidly in the most susceptible patients.

\section{Discussion and Lessons}

The LKD transplantation has become a mainstream treatment for ESKD; however, recent evidence has highlighted risks specially for some donor groups, as be for example the related donors. Risk of kidney donation include a poorly characterized CKD or even early ESRD. Glomerulonephritis is associated with poorly characterized molecular or genetic risks in those with normal renal function and may play and very important role in the poorly characterized genetic heredity risks associated to LKD.

Making pre-donation selection can be challenging and complex. It remains to be clarified if COL4A nephropathies play a role in the GN-ESRD in LKD. In addition is a not infrequent finding carriers of known mutations in COL4A, who did not develop any sign of kidney disease including urinary anomalies, this risk in relatives is a message to take into important consideration. The failure to characterize the primary renal disease also may contribute to the future risk.

There are an insufficient reported data COL4 entities and his repercussion on LKD. Gross, et al., describes seven mothers with AS who were evaluated because the initially controversy about if woman carrying AS may or may not be a donor [37], they conclude that a large part of these women will develop proteinuria and up to one third at 60 years will reach ESRD. They recommended only in cases of 40-50 years who not present microalbuminuria or hearing loss, it could be assessed as a donor after having ruled out other possible options [38], but to date, we firmly believe this recommendation pattern has been outdated and would be strongly based on a genetical study.

A case reported by Santos et al. describes a TBMN disorder on a transplant biopsy from two unrelated individuals [39] suggesting a not detected Col4A pathology in a donor without apparent familiar history.

Lentine et al. describe an increased risk for LKD about renal events like NS among African American donors, based on an 
analysis of a U.S. insurance database. A plausible interpretation done, like previously, is that African American donors are drawn from a group at higher underlying risk (even if disease free at the time of donation), and that this excess risk is not ameliorated by the selection process for donation. [15]. APOL1 genotyping could may play a role in safety living kidney donation in individuals with recent African ancestry $[40,41]$.

Scientific literature recently describes, as previously mentioned, that severe resistant NS and SFGS have been identified and related with COL44 mutations. The question is now if this GBM disorders are the main early glomerular problem of the LKD. Unfortunately, little we know about the true incidence of glomerulonephritis in LKD

Determining risk is critical for informing and select future donor candidate sand we show that in certain situations can be extremely challenging. The minimization of this risk will come in part from genetic characterization and molecular understanding of glomerular diseases with molecular genetic analysis with NGS or genome-wide association study (GWAS) techniques will certainly offer more appropriate information and permit to identified pathogenic variants or high-risk SNPs [42].

Several countries registries, including those with high donation rates, as for example in Spain, show an important decrease in the number of live donor transplants in recent years [43]. Why this occurs is unknow, but It is probably in some way clinician's confidence in this therapy is being lost. The best way to recover it is to show them that we can make a better and high specifically donor selection, excluding those groups with the highest genetic risk.

We aim encourage the reporting of all CKD or ESRD cases on the LKD population and propose a multicenter pilot study consisting perhaps of at least a genetic study of the related LKD or/and checking the MBG genes in every donor and to look for results on donor renal function and graft survival, including how many are dismissed for donors by targeted NGS.

\section{Conclusion}

we have to entering in a new prudent phase especially for some groups, still marked by enthusiasm to improve the lives of our patients but with the obligation to ensure that access to living kidney transplantation is done even better and safely.

\section{Acknowledgement}

None.

\section{Conflict of Interest}

The authors declare that they have no conflict of interest.

\section{References}

1. Cecka JM (2005) The OPTN/UNOS Renal Transplant Registry. Clin Transpl 1-16

2. Cecka JM (2008) Kidney transplantation in the United States. Clin Transpl 1-18.

3. Guirado L, Vela E, Cleries M, Diaz JM, Facundo C, et al. (2008) Why renal transplant from living donors gives better results than cadaver renal transplant? Nefrologia 28(2): 159-167.
4. Bia MJ, Ramos EL, Danovitch GM, Gaston RS, Harmon WE, et al. (1995) Evaluation of living renal donors: the current practice of US transplant centers. Transplantation 60(4): 322-327.

5. Leichtman A, Abecassis M, Barr M, Charlton M, Cohen D, et al. (2011) Living kidney donor follow-up: State-of-the-art and future directions, conference summary and recommendations. Am J Transplant 11: 25612568 .

6. Matas AJ, Bartlett ST, Leichtman AB, Delmonico FL (2003) Morbidity and mortality after living kidney donation, 1999-2001: survey of United States transplant centers. Am J Transplant 3(7): 830-834.

7. Segev DL, Muzaale AD, Caffo BS, Mehta SH, Singer AL, et al. (2010) Perioperative mortality and long-term survival following live kidney donation. JAMA 303(10): 959-966.

8. Siebels M, Theodorakis J, Schmeller N, Corvin S, Mistry Burchardi N et al. (2003) Risks and complications in 160 living kidney donors who underwent nephroureterectomy. NephDial Trans 18, (12): 2648-2654.

9. Brahim HN, Foley R, Rogers T, Bailey RF, Tan L, et al. (2009) Long-term consequences of kidney donation. N Engl J Med 360(5): 459-469.

10. Fehrman Ekholm I, Norden G, Lennerling A, Rizell M, Mjornstedt L, et al (2006) Incidence of end-stage renal disease among live kidney donors. Transplantation 82(12): 1646-1648.

11. Wafa EW, Refaie AF, Abbas TM, Fouda MA, Sheashaa HA, et al. (2011) End-stage renal disease among living-kidney donors: single-center experience. Exp Clin Transplant 9(1): 14-19.

12. Yalin SF, Trabulus S, Seyahi N, Cenzig M, Cicik ME, et al. (2018) Ambulatory Blood Pressure Monitoring in Living Kidney Donors: What Changes in 10 Years? Clin Trasplant 32(4): e13224.

13. O Keeffe LM, Ramond A, Oliver Williams C, Willeit P, Paige E, et al. (2018) Mid- and Long-Term Health Risks in Living Kidney Donors: A Systematic Review and Meta- analysis. Ann Inter Med 168(4): 276-284.

14. Muzaale AD, Massie AB, Wang MC, Montgomery RA, McBride MA, et al. (2014) Risk of end-stage renal disease following live kidney donation. JAMA 311(6): 579-586.

15. Cherikh WS, Young CJ, Kramer BF, Taranto SE, Randall HB, et al. (2011) Ethnic and gender related differences in the risk of end-stage renal disease after living kidney donation. Am J Transplant 11(8): 1650-1655.

16. Massie AB, Muzaale AD, Luo X, Chow EKH, Locke JE, et al. (2017) Quantifying Postdonation Risk of ESRD in Living Kidney Donors. JASN 28(9): 2749-2755.

17. Lentine K, Schnitzler MA, Xiao H, Saab G, Salvalaggio PR, et al. (2010) Racial Variation in Medical Outcomes among Living Kidney Donors. N Engl J Med 363(8): 724-732.

18. Lentine KL, Schnitzler MA, Garg AX, Huiling Xiao, David Axelrod, et al. (2015) Race, Relationship and Renal Diagnoses After Living Kidney Donation. Transplantation 99(8): 1723-1729.

19. Gibney EM, King AL, Maluf DG, Garg AX, Parikh CR (2007) Living kidney donors requiring transplantation: focus on African Americans. Transplantation 84(5): 647-649.

20. Cherikh WS, Young CJ, Kramer BF, Taranto SE, Randall HB, et al. (2011) Ethnic and gender related differences in the risk of end-stage renal disease after living kidney donation. Am J Transplant 11(8): 1650-1655.

21. Grams ME, Sang Y, Levey AS, Matsushita K, Ballew S, et al. (2016) Kidneyfailure risk projection for the living kidney-donor candidate. N Engl J Med 374: 411-421.

22. Locke JE, Reed RD, Massie A, MacLennan PA, Sawinski D, et al. (2017) Obesity increases the risk of end-stage renal disease among living kidney donors. Kidney international 91(3): 699-703.

23. Massie AB, Muzaale AD, Luo X, Chow EKH, Locke JE, et al. (2017) Quantifying Postdonation Risk of ESRD in Living Kidney Donors. JASN 28(9): 2749-2755.

24. Pek GXW, Ngoh CLY, Teo BW, Vathsala A, Goh BYS, et al. (2018) Visceral obesity in Asian living kidney donors significantly impacts early renal function after donor nephrectomy. World J Urol 37(10): 2231-2236. 
25. Matas AJ, Berglund DM, Vock DM, Ibrahim HN (2018) Causes and timing of end-stage renal disease after living kidney donation. Am J Transplant 18(5): 1140-1150.

26. Anjum S, Muzaale AD, Massie AB, Bae S, Luo X, et al. (2016) Patterns of End-Stage Renal Disease Caused by Diabetes, Hypertension, and Glomerulonephritis in Live Kidney Donors. Am J Transplant 16(12): 3540-3547.

27. AL Kennard, SH Jiang, GD Walters (2017) Increased glomerulonephritis recurrence after living related donation. BMC Nephrology 18(1): 25

28. Shankland SJ, Pollak MR (2011) A suPAR circulating factor causes kidney disease. Nat Med 17(8): 926-927.

29. Hayek SS, Quyyumi AA, Reiser J (2016) Soluble Urokinase Receptor and Chronic Kidney Disease. N Engl J Med 374(9): 891.

30. Kofman T, Audard V, Narjoz C, Gribouval O, Matignon M, et al. (2014) APOL1 polymorphisms and development of CKD in an identical twin donor and recipient pair. Am J Kidney Dis 63(5): 816-819.

31. Clark EG, Knoll G, Bugeja A, Burns KD, Scofield RH (2015) Lupus After Kidney Donation: A Case Report with Implications for the Evaluation of Potential Donors with a Family History of Lupus. Transplantation 99(4): e27-e28.

32. L Papazachariou, G Papagregoriou, D Hadjipanagi, P Demosthenous, $\mathrm{K}$ Voskarides, et al. (2017) Frequent COL4 mutations in familial microhematuria accompanied by later-onset Alport nephropathy due to focal segmental glomerulosclerosis. Clin Genet 92(5):517-527.

33. Constantinos Deltasa, Isavella Savvaa, Konstantinos Voskaridesa, Louiza Papazacharioua, Alkis Pierides (2015) Carriers of Autosomal Recessive Alport Syndrome with Thin Basement Membrane Nephropathy Presenting as Focal Segmental Glomerulosclerosis in Later Life. Nephron 130(4): 271-280.

34. Voskarides K, Damianou L, Neocleous V, Zouvani I, Christodoulidou S, et al. (2007) COL4A3/COL4A4 mutations producing focal segmental glomerulosclerosis and renal failure in thin basement membrane nephropathy. J Am Soc Nephrol 18(11): 3004-3016.

35. Consolacion Rosado, Elena Bueno, Carmen Felipe, Rogelio Gonzalez S (2014) COL4A4 gene study of a European population: description of new mutations causing autosomal dominant Alport syndrome. Int J Mol Epidemiol Genet 5(4): 177-184.

36. Ilaria Longo, Paola Porceda, Francesca Mari, Daniela Giachino, Ilaria Meloni, et al. (2002) COL4A3/COL4A4 mutations: From familial hematuria to autosomal-dominant or recessive Alport syndrome. Kidney Int 61(6): 1947-1956.

37. Yachnin T, Iaina A, Schwartz D, Nakache R (2002) The mother of an Alport's syndrome patient: a safe kidney donor?. Nephrol Dial Transplant 17(4): 683-684

38. Gross 0, Weber M, Fries J, Muller GA (2009) Living donor kidney transplantation from relatives with mild urinary abnormalities in Alport syndrome: long term risk, benefit and outcome. Nephrol DialTransplant 24(5): 1626-1630.

39. S Santos, S Marques, T Golper, A Langon, AB Fogo (2017) Thin Glomerular Basement Membrane in a Kidney Transplant of an Alport's Syndrome Patient: A Case Report. Transplant Proc 49(10): 2384-2387.

40. Ma L, Divers J, Freedman BI (2018) Mechanisms of injury in APOL1associated kidney disease. Transplantation 103(3): 487-492.

41. Gordon EJ, Amortegui D, Blancas I, Wicklund C, Friedewald J, et al. (2018) African American Living Donors' Attitudes About APOL1 Genetic Testing: A Mixed Methods Study. Am J Kidney Dis 72(6): 819-833.

42. CP Thomas, MA Mansilla, R Sompallae, SO Mason, CJ Nishimura, et al. (2017) Screening of Living Kidney Donors for Genetic Diseases Using a Comprehensive Genetic Testing Strategy. Am J Transplant 17(2): 401410.

43. http://www.senefro.org/contents/webstructure/InformeREER_2016_ BURGOS.pdf 